\title{
Publisher Correction: The life cycle of non-polio enteroviruses and how to target it
}

Jim Baggen, Hendrik Jan Thibaut, Jeroen R. P. M. Strating (D) and

Frank J. M. van Kuppeveld

Nature Reviews Microbiology (2018) https://doi.org/10.1038/s41579-018-0005-4

Published online 6 April 2018

In the version of this Review originally published, co-author Hendrik Jan Thibaut's name was incorrectly indexed as "Jan Thibaut, H". It should have appeared as "Thibaut, HJ". This has now been corrected in all versions of the Review. The publisher apologizes to the authors and to readers for this error.

https://doi.org/10.1038/s41579-018-0022-3 I Published online 03 May 2018

\section{Correction: Bridging the gap for lipopolysaccharides}

\section{Katharine H. Wrighton}

Nature Reviews Microbiology (2018) https://doi.org/10.1038/nrmicro.2018.30

Published online 5 March 2018

The image that accompanies this article was wrongly credited to Macmillan Publishers Limited in the online version. The correct credit is iStockphoto. This has now been corrected online. We apologize to the readers for any confusion caused.

https://doi.org/10.1038/s41579-018-0023-2 I Published online 03 May 2018 